\title{
Sensitization to Common Food Allergens in Makkah City
}

\author{
Moufag Mohammed Saeed Tayeb , Emad A Koshak, Majdy Mohammed .A Qutub \\ King Abdul Aziz University Hospital - Jeddah - Saudi Arabia , Albaha University- \\ Kingdome of Saudi Arabia King Abdul Aziz University Hospital - Jeddah
}

\begin{abstract}
Sensitization to food allergens at Makkah city is not documented. In this study, a retrospective evaluation of a specific $\operatorname{IgE}(\mathrm{sIgE})$ test results to common food allergens of 80 patients with suspected food allergy (FA) was conducted. Of these, $51(63.75 \%)$ were female, $29(36.25 \%)$ male, $48(60.6 \%)$ adult and $31(39.4 \%)$ pediatric patients. Their ages ranged between 1 month of age and 75 years (mean 27 years and median 30 years). Their common diagnoses were $52(65 \%)$ atopic dermatitis, $24(30 \%)$ urticaria/angioedema and $4(5 \%)$ bronchial asthma. Atopic history in the first and second-degree relatives was positive in 35 (43.75\%). The top five food allergens were cocoa $22(27.5 \%)$, peanuts $14(17.5 \%)$, egg white $12(15 \%)$, milk $10(12.5 \%)$ and strawberry $9(11.3 \%)$. In conclusion, sensitization to common food allergens in Makkah was compatible with worldwide literature except for cocoa and strawberries, which are an unexpected finding that needs further evaluation.
\end{abstract}

\section{Introduction}

The actual prevalence in adults confirmed by double blind placebo controlled food challenge (DBPCFC) has been estimated to be $1.4 \%$ (Bindslev-Jensen C 1998). FA is more common in children than adults (Bock SA 1982, 1987). Impact of FA on the quality of life depends on how easy it is to avoid the related food. Avoidance can prevent the disease but it can be a difficult job and impinge on the individual's social activities as well as nutrition. FA is more common in patients with other atopic diseases. For example, in children, $10 \%$ of asthmatics have (FA) and $30 \%$ with atopic dermatitis have had an adverse reaction to food (Sampson HA 1999a, 1999b). In this study, the aim was to describe the prevalence of sensitisation to common food allergens and their related allergic disorders.
The prevalence of allergic disease has increased markedly over the last 50 years (Meyer R 2008). Although our knowledge about pathogenesis, risk factors and treatment strategies, the increase of prevalence of the allergic diseases could not be prevented (ISAAC 1998). The term allergen denotes a protein or glycoprotein that can induce (sIgE) response and react with the resulting antibody molecules (Durham SR 2001). Food Allergy (FA) appears to be strongly influenced by genetics but the basis of the genetic predisposition has not explained the prevalence of FA satisfactorily. This fact opens the possibility of the influence of the environmental factors on FA like (external, maternal, and gastrointestinal environment) (Dreskin SC 2006). FA prevalence is perceived to be very common; however, its prevalence is low. 


\section{Material and Methods}

The study group was selected from all pediatric and adult patients referred because of allergic disorders with the suspicion of food allergy to AL BORG laboratory in Makkah city between October 2005 and July 2007. SIgE in-vitro tests to common food allergens of 80 patients were evaluated retrospectively. The common food panel included: nuts mix (hazelnut, peanuts, walnut, almond, pecan nut, pistachionut and cashew), milk and dairy products like (cheese mix, casein), fruits (orange, peach, cherry, bananas, strawberries, mango, apple and fruits mix), vegetables (potato, celery, carrot, tomato, onion and vegetable mix), egg (yolk, white), sea food (cod fish, crab, fish/shellfish/muluscous and shrimp), grains (gluten, green beans, wheat flour, rye flour, sesame seed, soya beans and maize), meat (lamb, chicken), plant (cacoa, yeast and mustard) and others (bovine serum albumin, ammeltesc, honey and meals mix). Blood was extracted and tested with RIDA® Allergy Screen of RBiopharm. This screen is an efficient and highly economic system for the diagnostic confirmation of allergies. It offers test methods for the antibody detection by an immunoblot with four different panels (panel 1 - 4) with 20 allergens each. The evaluation was done automatically by digital pictures in RIDA® X-Screen or RIDA ${ }^{\circledR}$ maXi-Screen. SIgE results were evaluated between zero and six classes according to the severity of allergic reaction to each food.

\section{Results}

SIgE food tests of 80 patients were evaluated retrospectively. Of these patients, $51(63.75 \%)$ were female, 29 $(36.25 \%)$ male, $48(60.6 \%)$ adult and 31 (39.4\%) pediatric patient. Patients were aged between 1 month of age and 75 years (mean 27 years and median 30 years). SIgE food test were evaluated as negative in $8(10 \%)$ patients. The common allergy diagnoses were $52(65 \%)$ atopic dermatitis, $24(30 \%)$ urticaria and angioedema, 4 (5\%) bronchial asthma. Thirty-five patients $(43.75 \%)$ had atopy history in their first and second-degree relatives. In this study, $27.5 \%$ of the patients were allergic to cacoa, $17.5 \%$ to peanuts. Egg white sensitivity was found at a rate of $15 \%$, milk sensitivity was 12.5 $\%$ and strawberries sensitivity was 11.25 $\% .8 .75 \%$ of patients were sensitive to onion and $7.5 \%$ to orange and mango. Carrot, wheat flour and tomato sensitivity was found at a rate of $6.25 \%$ and nut, bananas, egg yolk, cod fish and soya beans sensitivity was $5 \%$ and hazelnut, pistachionut,casein,fish/shellfish/muluscou $\mathrm{s}$, green beans, chicken and yeast sensitivity was $3.75 \%$ and cashew, cheese mix, potato, shrimp, seasame seed and lamb sensitivity was found at a rate of 2.5 $\% .1 .25 \%$ of the patients were sensitive to almond, peach, cherry, apple, celery, bovine serum albumin, honey, ammeltesc, mustard and meals mix and zero \% to walnut, pecan nut, fruits mix, vegetable mix, crab, gluten, rye flour and maize (table 1). 
Moufag Mohammed etal

Table-1

Results of sIgE to common food allergens

\begin{tabular}{|c|c|c|c|c|c|c|c|}
\hline \multirow[t]{2}{*}{ Food Allergens } & \multirow[t]{2}{*}{ Negative } & \multicolumn{6}{|c|}{ Positive } \\
\hline & & Low & increased & high & $\begin{array}{l}\text { Very } \\
\text { high }\end{array}$ & Total & $\%$ \\
\hline Cocoa & 8 & 19 & 3 & & & 22 & 27.5 \\
\hline Peanuts & 55 & 8 & 3 & 1 & 2 & 14 & 17.5 \\
\hline Egg white & 58 & 9 & 2 & 1 & & 12 & 15 \\
\hline Milk & 60 & 6 & 3 & 1 & & 10 & 12.5 \\
\hline Strawberries & 32 & 6 & 3 & & & 9 & 11.3 \\
\hline Onion & 22 & 5 & 2 & & & 7 & 8.8 \\
\hline Orange & 55 & 4 & 1 & & 1 & 6 & 7.5 \\
\hline Mango & 30 & 4 & 2 & & & 6 & 7.5 \\
\hline Carrot & 48 & 3 & 2 & & & 5 & 6.3 \\
\hline Wheat flour & 55 & 1 & 2 & 2 & & 5 & 6.3 \\
\hline Tomato & 63 & 1 & 3 & 1 & & 5 & 6.3 \\
\hline Nut & 21 & 2 & 1 & 1 & & 4 & 5 \\
\hline Bananas & 26 & 3 & & 1 & & 4 & 5 \\
\hline Egg yolk & 65 & 4 & & & & 4 & 5 \\
\hline Cod fish & 40 & 4 & & & & 4 & 5 \\
\hline \begin{tabular}{|l|} 
Soya beans \\
\end{tabular} & 54 & 1 & 2 & & 1 & 4 & 5 \\
\hline Hazelnut & 34 & & 1 & 1 & 1 & 3 & 3.8 \\
\hline PistachioNut & 5 & 2 & 1 & & & 3 & 3.8 \\
\hline Casein & 41 & 1 & 1 & 1 & & 3 & 3.8 \\
\hline Fish/shellfish/muluscous & 17 & & 2 & 1 & & 3 & 3.8 \\
\hline Green beans & 1 & 1 & 1 & & 1 & 3 & 3.8 \\
\hline Chicken & 26 & 1 & 2 & & & 3 & 3.8 \\
\hline Yeast & 25 & 3 & & & & 3 & 3.8 \\
\hline Cashew & 5 & 1 & 1 & & & 2 & 2.5 \\
\hline Cheese mix & 5 & & 2 & & & 2 & 2.5 \\
\hline \begin{tabular}{|l|} 
Potato \\
\end{tabular} & 35 & & & 1 & 1 & 2 & 2.5 \\
\hline Shrimp & 25 & 1 & 1 & & & 2 & 2.5 \\
\hline Sesame seed & 39 & 1 & 1 & & & 2 & 2.5 \\
\hline Lamb & 13 & 1 & 1 & & & 2 & 2.5 \\
\hline Almond & 36 & 1 & & & & 1 & 1.3 \\
\hline Peach & 5 & & 1 & & & 1 & 1.3 \\
\hline Cherry & 5 & & & 1 & & 1 & 1.3 \\
\hline Apple & 44 & & 1 & & & 1 & 1.3 \\
\hline Celery & 39 & & 1 & & & 1 & 1.3 \\
\hline Bovine serum albumin & 1 & 1 & & & & 1 & 1.3 \\
\hline Honey & 5 & 1 & & & & 1 & 1.3 \\
\hline Ammeltesc & & 1 & & & & 1 & 1.3 \\
\hline Mustard & 12 & & 1 & & & 1 & 1.3 \\
\hline Meals mix & 6 & 1 & & & & 1 & 1.3 \\
\hline Walnut & 37 & & & & & & 0 \\
\hline Pecan nut & 5 & & & & & & 0 \\
\hline Fruits mix & 5 & & & & & & 0 \\
\hline Vegetable mix & 5 & & & & & & 0 \\
\hline Crab & 27 & & & & & & 0 \\
\hline \begin{tabular}{|l|} 
Gluten \\
\end{tabular} & 5 & & & & & & 0 \\
\hline Rye flour & 31 & & & & & & 0 \\
\hline Maize & 4 & & & & & & 0 \\
\hline
\end{tabular}




\section{Discussion}

Wevaluated the prevalence of FA and family history of atopy and its relation to atopic dermatitis, urticaria, angioedema and asthma in Saudi population living in and around Makkah city. In this study, the top five food allergens were cocoa, peanuts, egg white, milk and strawberry. FA usually manifests in early childhood as part the atopic march and is more prevalent in children due to the immature gastrointestinal epithelial membrane barrier allowing more proteins through the barrier and into circulation (Suzuki K et al 2002, Meyer R 2008). Except possible allergy to cocoa and strawberry, this retrospective study results to some extent resemble most of the worldwide results. One study showed that the most common food allergies in adults are shellfish, peanuts, tree nuts, fish, and eggs while the most common food allergies in children are milk, eggs, peanuts, and tree nuts (National Institute of Allergy and Infectious Diseases July 2004). In another study, the top five allergens in caucasian and non-caucasian children were egg, peanut, tree nut, milk and fish (Dias RP et al 2008). In contrast Indian food triggers differ from Makkah ones which are mainly apples and hazelnuts (Somani VK 2008). We are not yet convinced that cocoa is the commonest food causing allergy in Makkah because allergies to cacao (the bean that is the main ingredient in chocolate) are possible but so rare as to be virtually nonexistent in recent medical literature (cederberg 2004). Allergy to chocolate happen mainly because it contains a trace amounts of allergens which can trigger allergy like milk, peanuts, treenuts, wheat, soy, corn, fruits, caffeine and due to drug interactions like itchiness in people on Prozac (flouxetine ${ }^{\circledR}$ ) (cederberg 2004). Chocolates contain undeclared allergens, which triggers allergy like hazelnut and peanut traces (Pele M 2007). Immunoblot technique allowed the detection of less than 0.5 milligram of hazelnut or almond proteins per 100 gram of chocolate (Scheibe B 2001). Peanut allergy (e PA) is associated with greater risk of anaphylaxis
(Khodoun M et al 2009). (PA) patients have to avoid other nuts also because of the cross reactivity. Cashew and pistachio nuts do cross with each others so allergy reactions for both should be examined (Hasegawa M 2009). The major peanut allergen (Ara h 2) shares common IgEbinding epitopes with almond and brazil nut allergens, which may contribute to the high incidence of tree nut sensitization in peanut allergic individuals (de Leon MP 2006). Egg white (EW) allergy is mainly due to its protein contents. High sIgE to EW proteins like (ovomucoid, ovalbumin, ovotransferrin and lysozyme) and its components in the blood isn't necessarily efficient for the diagnosis or the prediction of the outcome of egg allergy in children (Urisu A et al 1999). Cow's milk allergy (CMA) is the main cause of (FA) in infants and young children. It can be mediated through $\operatorname{IgE}$ or non- $\operatorname{IgE}$ mechanisms. It is estimated that up to $50 \%$ of pediatric (CMA) is non-IgE-mediated. IgE-mediated (CMA) children are usually atopic (Maloney J 2007). Breast-feeding have been shown to be protective in preventing food allergy. Infants who are breast-fed have lower serum IgE levels (Buonocore et al, 1992) and have less allergic illness in early childhood (Burr et al, 1993) and possibly through to adolescence (Saarinen and Kajosaari, 1995). Breast-fed infants have also been found to have less sensitization to house dust mites at the age of one year (Kramer 1988). Complete elimination the offending allergen is the mainstay of management of patients with FA (Edlich RF 2008). Patients with FA education involved teaching the mother to avoid high risk situations, encouraging the child to wear a medic alert bracelet, and teaching the family and child to recognize early symptoms of allergic reactions and to manage an anaphylactic reaction, including the use of self injectable epinephrine, as well as activating emergency services (Clark AT 2009). The only proven treatment for cow's milk allergy (CAM) is the complete elimination of cows' milk proteins (CMPs) from the diet by means of hypoallergenic formulas 
and ensuring that essential dietary requirements are met (Curciarello R 2008, Yu JW 2006, Crittenden RG 2005). Soy formula is recommended as first alternative for infants over 6 months of age with immediate food reactions (Kemp AS et al 2008). Regular consumption of fruits has a positive influence on human health by disease prevention. However, IgE-mediated fruit allergies have been shown to be an increasing health risk for children and adults. Strawberry and fruit proteins can result in a production of similar epitopes to IgEs and consequently in cross-reactivity (Marzban G 2005). In conclusion, (sIgE) antibodies tests to common food were evaluated retrospectively in patients who have allergic disease in Makkah city and around. Our data indicate that the top food allergens in Makkah were cocoa, peanuts, egg white, milk and strawberry. Sensitization to common food allergens in Makkah was compatible with world wide literature except for cocoa and strawberries which is an unexpected finding that needs further evaluation.

\section{Acknowledgments}

We thank AL BORG clinical immunology laboratory in Makkah city as well as Hatim Subhi and Ahmed Mansoor for their assistance in data collection. Hatim and Ahmed are health workers in this laboratory and collected RAST (sIgE) food test results of 80 patients retrospectively, supplied us with a table which contains the patient names, age, sex, primary allergy diagnosis and mobile phones. This laboratory is one of the best in allergy and immunology clinical area in Makkah and most of Saudi countries.

\section{$\underline{\text { References }}$}

1. Bindslev-Jensen C (1998). Food Allergy ABC of Allergies. British Medical Journal , 316 (1299): 44-47

2. Bock SA (1982). The natural history of food sensitivity. Journal of Allergy and Clinical Immunology, 69 (2): 173-177.

3. Bock SA (1987). Prospective appraisal of complaints of adverse reactions to foods in children during the first 3 years of life. Journal of Pediatrics, 79 (5): 683-688

4. Buonocore G, Zani S, Tomasini B, et al (1992). Serum IgE concentrations in the neonatal period. Biology of the Neonate, 62 (1): 10-14

5. Burr ML, Limb ES, Maguire MJ et al (1993). Infant feeding, wheezing and allergy: a prospective study. Archives of Disease in Childhood, 68 (6): 724-728

6. Cederberg, Jonas, et al. 2004 "Itch and Skin Rash from Chocolate During Fluoxetine and Sertraline Treatment: Case Report." BMC Psychiatry. 4:36.

7. Clark AT, Islam S, King Y, Deighton J, Anagnostou K, Ewan PW2009. Successful oral tolerance induction in severe peanut allergy. Allergy.. [Epub ahead of print]

8. Crittenden RG, Bennett LE 2005. Cow's milk allergy: a complex disorder. J Am Coll Nutr. 24(6):582S-91S.

9. Curciarello R, Lareu JF, Fossati CA, Docena GH, Petruccelli S 2008. Immunochemical characterization of Glycine max L. Merr. var Raiden, as a possible hypoallergenic substitute for cow's milk-allergic patients. Clin Exp Allergy. (9):1559-65. Epub 2008 Jul 9.

10. de Leon MP, Drew AC, Glaspole IN, Suphioglu C, O'Hehir RE, Rolland JM 2007. IgE cross-reactivity between the major peanut allergen Ara h 2 and tree nut allergens. Mol Immunol.;44(4):463-71.

11. Dias RP, Summerfield A, Khakoo GA 2008. Food hypersensitivity among Caucasian and non-Caucasian children. Pediatr Allergy Immunol.;19(1):86-9.

12. Dreskin SC 2006. Genetics of food allergy. Curr Allergy Asthma Rep.;6(1):58-64.

13. Durham SR, Church MK 2001. Principles of allergy diagnosis. In: Holgate ST, Church MK, Lichtenstein LM, eds. Allergy. 2nd edition. Philadelphia: Mosby,;3-16.

14. Edlich RF, Cochran AA, Greene JA, Woode DR, Gubler KD 2008, Long WB 3rd. Advances in the Treatment of Peanut Allergy: A Case Report. J Emerg Med. [Epub ahead of print]

15. Hasegawa M, Inomata N, Yamazaki H, Morita A, Kirino M, Ikezawa Z 2009. Clinical Features of Four Cases with Cashew Nut Allergy and Cross-Reactivity between Cashew Nut and Pistachio. Allergol Int.;58(2). [Epub ahead of print]

16. The International Study of Asthma and Allergy in Childhood (ISAAC) Steering Committee. Worldwide variation in prevalence of symptoms of asthma, allergic rhinoconjunctivitis, and atopic eczema: ISAAC. Lancet :351:1225-32.

17. Kemp AS, Hill DJ, Allen KJ, Anderson K, Davidson GP, Day AS, Heine RG, Peake JE, Prescott SL, Shugg AW, Sinn JK2008; Australian consensus panel. 
Guidelines for the use of infant formulas to treat cows milk protein allergy: an Australian consensus panel opinion. Med J Aust.;188(2):109-12.

18. Khodoun M, Strait R, Orekov T, Hogan S, Karasuyama H, Herbert DR, Köhl J, Finkelman FD2009. Peanuts can contribute to anaphylactic shock by activating complement. J Allergy Clin Immunol.;123(2):352-3.

19. Kondo M, Suzuki K, Inoue R, Sakaguchi H, Matsukuma E, Kato Z, Kaneko H, Fukao T, Kondo N 2005. Characterization of T-cell clones specific to ovomucoid from patients with eggwhite allergy. J Investig Allergol Clin Immunol. 2005;15(2):107-11.

20. Kramer MS (1988). Does breast feeding help protect against atopic disease? Biology, methodology, and a golden jubilee of controversy. Journal of Pediatrics, 112; (2): 181-190.

21. Maloney J, Nowak-Wegrzyn A 2007. Educational clinical case series for pediatric allergy and immunology: allergic proctocolitis, food protein-induced enterocolitis syndrome and allergic eosinophilic gastroenteritis with protein-losing gastroenteropathy as manifestations of non-IgE-mediated cow's milk allergy. Pediatr Allergy Immunol. Jun;18(4):3607.

22. Marzban G, Mansfeld A, Hemmer W, Stoyanova E, Katinger H, da Câmara Machado ML2005; . Fruit cross-reactive allergens: a theme of uprising interest for consumers' health. Biofactors 23(4):23541.

23. Meyer R 2008. New guidelines for managing cow's milk allergy in infants. $\mathrm{J}$ Fam Health Care.;18(1):27-30.

24. Monti G, Libanore V, Marinaro L, Lala R, Miniero R, Savino F 2007. Multiple bone fractures in an 8-year-old child with cow's milk allergy and inappropriate calcium supplementation. Ann Nutr Metab.;51(3):228-31.

25. National Institute of Allergy and Infectious Diseases (2004). "Food Allergy: An Overview" (PDF).
26. Pele M, Brohée M, Anklam E, Van Hengel AJ 2007. Peanut and hazelnut traces in cookies and chocolates: relationship between analytical results and declaration of food allergens on product labels. Food Addit Contam. (12):1334-44.

27. Saarinen UM, Kajosaari M (1995). Breastfeeding as prophylaxis against atopic disease: prospective follow-up study until 17 years old. Lancet, 346; (8982): 1065-1069

28. Sampson HA (1999a). Food allergy. Part 1: Immunopathogenesis and clinical disorders. Journal of Allergy and Clinical Immunology 103: (5) : 717-728

29. Sampson HA(1999b). Food allergy. Part 2: Diagnosis and management. Journal ofAllergy and Clinical Immunology 103; (6): 981-989

30. Scheibe B, Weiss W, Ruëff F, Przybilla B, Görg A 2001. Detection of trace amounts of hidden allergens: hazelnut and almond proteins in chocolate. $\underline{\mathbf{J}}$ Chromatogr B Biomed Sci Appl. 756(12):229-37.

31. Somani VK. A 2008 . study of allergenspecific IgE antibodies in Indian patients of atopic dermatitis. Indian J Dermatol Venereol Leprol.;74(2):100-4.

32. Suzuki K, Inoue R, Sakaguchi H, Aoki M, Kato Z, Kaneko H, Matsushita S, Kondo $N$ 2002. The correlation between ovomucoid-derived peptides, human leucocyte antigen class II molecules and T cell receptor-complementarity determining region 3 compositions in patients with egg-white allergy. Clin Exp Allergy.;32(8):1223-30.

33. Urisu A, Yamada K, Tokuda R, Ando H, Wada E, Kondo Y, Morita Y 1999. Clinical significance of IgE-binding activity to enzymatic digests of ovomucoid in the diagnosis and the prediction of the outgrowing of egg white hypersensitivity. Int Arch Allergy Immunol.;120(3):192-8.

34. Yu JW, Pekeles G, Legault L, McCusker CT 2006. Milk allergy and vitamin D deficiency rickets: a common disorder associated with an uncommon disease. Ann Allergy Asthma Immunol;96(4):615-9. 


\section{حساسية|لطعام بمكة}

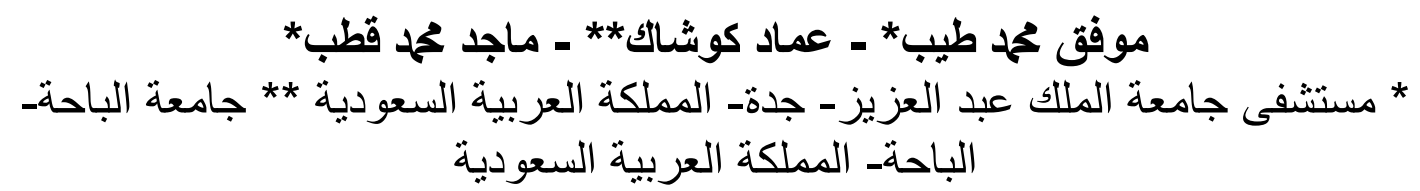

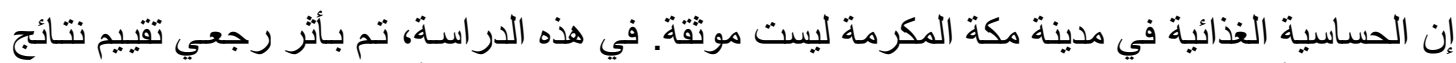

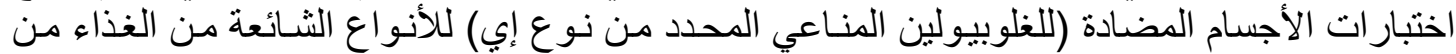

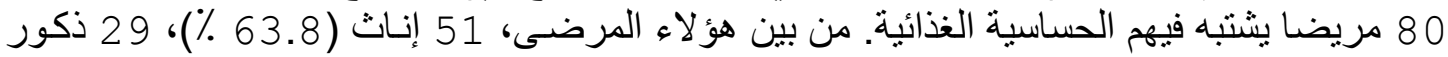

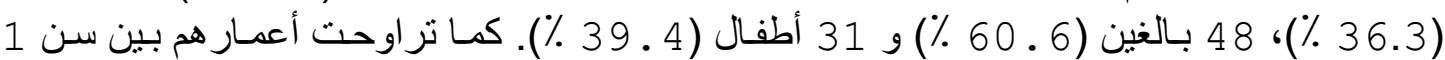

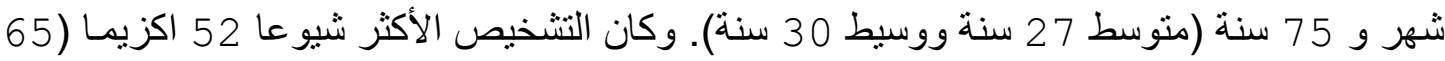

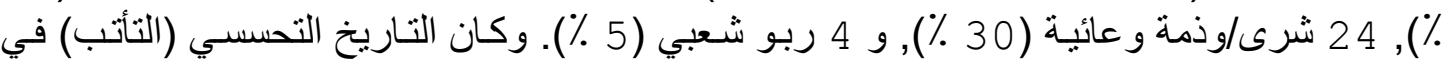

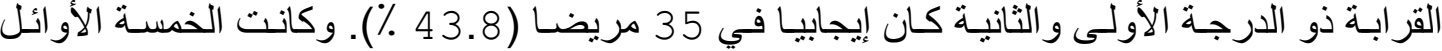

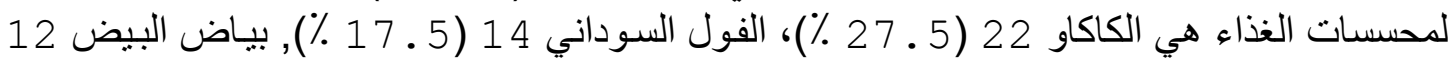

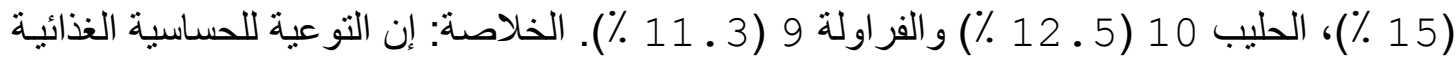

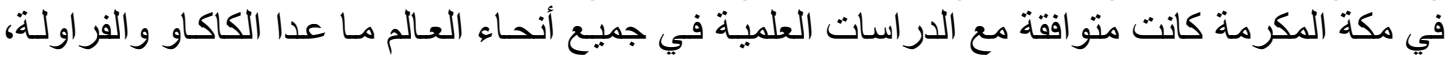

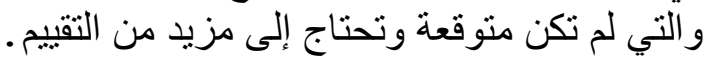

